\title{
Briófitas do Parque Nacional da Restinga de Jurubatiba, RJ, Brasil ${ }^{1}$
}

\author{
Caio Amitrano de Alencar Imbassahy 2,5 , Denise Pinheiro da Costa ${ }^{3}$ e Dorothy Sue Dunn de Araujo ${ }^{4}$
}

Recebido em 17/12/2007. Aceito em 23/10/2008

\begin{abstract}
RESUMO - (Briófitas do Parque Nacional da Restinga de Jurubatiba, RJ, Brasil). Este trabalho representa uma síntese do conhecimento florístico de briófitas do Parque Nacional da Restinga de Jurubatiba, com resultados de campo, material de herbário e publicações. Foram registrados 61 táxons de briófitas, pertencentes a 15 famílias e 33 gêneros. Para cada táxon foram analisados a distribuição geográfica, o tipo de substrato e a forma de vida. A família predominante foi Lejeuneaceae (25 espécies), seguida de Jubulaceae (sete), Calymperaceae (quatro) e Sphagnaceae (quatro). Entre as espécies, predominaram as de distribuição Neotropical (35\%). Com relação ao substrato preferencial, a maior parte dos táxons é corticícola. A forma de vida predominante foi o tapete, seguido pelo tufo e a trama. O Parque possui brioflora bastante representativa no que diz respeito à vegetação de restinga, com 45\% dos táxons de briófitas conhecidas para as restingas no Brasil e $82 \%$ das conhecidas para as restingas do estado do Rio de Janeiro. É apresentada uma chave para identificação das espécies.
\end{abstract}

Palavras-chave: florística, hepáticas, musgos, restinga, Rio de Janeiro

\begin{abstract}
Bryophytes of Restinga de Jurubatiba National Park, Rio de Janeiro State, Brazil). We present a synthesis of the bryophyte flora in Restinga de Jurubatiba National Park, based on field work, herbaria material and bibliography. Sixty one taxa were recorded, in 15 families and 33 genera. For each taxa, we analyze geographic distribution, substrata and life form. The most species-rich family was Lejeuneaceae (25 species), followed by Jubulaceae (seven), Calymperaceae (four) and Sphagnaceae (four). Most taxa have a Neotropical (35\%) distribution, and most taxa prefer the corticicolous substrate. Mat was the most common life form. The bryoflora of this National Park is an important reservoir of bryophyte diversity in the restingas, with $45 \%$ of the taxa known from the sandy coastal plains of Brazil and $82 \%$ known from the this habitat in Rio de Janeiro state. A key to identification of the species is given.
\end{abstract}

Key words: flora, Liverworts, mosses, restinga, Rio de Janeiro State

\section{Introdução}

As restingas ou planícies litorâneas arenosas quaternárias ocupam ca. $79 \%$ da costa brasileira (Lacerda et al. 1993), num total de $5.000 \mathrm{~km}$ de extensão (Lacerda et al. 1984). No Estado do Rio de Janeiro, ocupam ca. $1200 \mathrm{~km}^{2}$, ou aproximadamente 2,8\% da área total do Estado (Araujo \& Maciel 1998). Estão incluídas no domínio da Mata Atlântica, que atualmente ocupa ca. 19\% do território do Estado, contra os ca. $97 \%$ estimados para o período anterior à colonização portuguesa (Fundação SOS Mata Atlântica/Instituto Nacional de Pesquisas Espaciais 2002).

Existe um grande número de Unidades de Conservação que protegem as restingas no Estado do Rio de Janeiro, como a Área de Proteção Ambiental da Massambaba, a Área de Proteção Ambiental de Maricá, o Parque Nacional da Restinga de Jurubatiba, o Parque
Estadual da Ilha Grande, a Reserva Biológica da Praia do Sul e a Reserva Ecológica da Juatinga. O Parque Nacional da Restinga de Jurubatiba (PNRJ) tem a maior área de restinga incluída em uma Unidade de Conservação no Estado e abriga uma das 12 áreas (site 5) do Programa Brasileiro de Pesquisas Ecológicas de Longa Duração (PELD/MCT-CNPq).

Diversos projetos de pesquisa em zoologia, botânica e ecologia são desenvolvidos no litoral norte do Estado desde a década de 1980, intensificando-se a partir da criação do PNRJ em 1998. A atuação de instituições como o Museu Nacional do Rio de Janeiro, Universidade Federal do Rio de Janeiro, Universidade do Estado do Rio de Janeiro, Universidade Estadual Norte Fluminense e, especialmente, do Núcleo em Ecologia e Desenvolvimento Sócio-Ambiental de Macaé (NUPEM/UFRJ), tornou esta região uma das áreas de restinga mais bem estudadas do litoral brasileiro (Jamel 2004).

\footnotetext{
1 Parte da Dissertação de Mestrado do primeiro Autor

2 Universidade Federal do Rio de Janeiro, Museu Nacional do Rio de Janeiro, Quinta da Boa Vista s.n., 20940-040 São Cristóvão, Rio de Janeiro, RJ, Brasil

3 Instituto de Pesquisas Jardim Botânico do Rio de Janeiro, Rua Pacheco Leão 915, 22460-030 Jardim Botânico, Rio de Janeiro, RJ, Brasil

4 Universidade Federal do Rio de Janeiro, Centro de Ciências da Saúde, Departamento de Ecologia, Laboratório de Ecologia Vegetal, C. Postal 68020, 21941-590 Ilha do Fundão, Rio de Janeiro, RJ, Brasil

5 Autor para correspondência: caioimba@ hotmail.com
} 
No que diz respeito ao conhecimento das briófitas de restingas no Estado do Rio de Janeiro e no Brasil, as informações disponíveis encontram-se nos trabalhos de Behar et al. (1992) e Visnadi \& Vital (1995) para a restinga de Setiba (Espírito Santo), Yano \& Costa (1993) para a restinga de Massambaba (Rio de Janeiro), Vital \& Visnadi (1993) para um trecho de restinga da Estação Ecológica de Juréia-Itatins (São Paulo), Visnadi (2004) para as praias do Estado de São Paulo, Yano \& Peralta (2004) para a restinga da Barra do Ribeira (São Paulo), Bastos \& Yano (2006) para algumas regiões litorâneas da Bahia e Costa et al. (2006) para as restingas do estado do Rio de Janeiro. No total, são conhecidos 131 táxons de briófitas para as restingas do Brasil, dos quais 63 (Costa et al. 2006) ocorrem o Estado do Rio de Janeiro.

A flora do PNRJ compõe-se de 588 táxons de angiospermas, 31 de pteridófitas 147 de algas continentais (Costa \& Dias 2001), e 55 espécies de briófitas (Costa \& Yano 1998; Costa et al. 2006).

Este trabalho tem por objetivo ampliar o conhecimento da brioflora do PNRJ e fornecer uma chave de identificação para os táxons encontrados.

\section{Material e métodos}

O Parque Nacional da Restinga de Jurubatiba localiza-se no litoral da região Norte Fluminense do Estado do Rio de Janeiro, na planície costeira do rio Paraíba do Sul (Muehe \& Valentini 1998), entre as coordenadas $22^{\circ} 00^{\prime}-22^{\circ} 23^{\prime} \mathrm{S}$ e $41^{\circ} 15^{\prime}-41^{\circ} 45^{\prime} \mathrm{W}$, abrangendo parte dos municípios de Macaé, Quissamã e Carapebus, com área total de $148,6 \mathrm{~km}^{2}$. A região apresenta precipitação média anual de $1.300 \mathrm{~mm}$, concentrando-se nos meses de primavera e verão (Esteves et al. 2002). A temperatura média anual é de $22,6{ }^{\circ} \mathrm{C}$ (Araujo et al. 1998). A restinga do PNRJ compreende um mosaico de formações abertas organizadas em ilhas e formações florestais de restinga, além de ecossistemas aquáticos (lagoas de água doce e salobras), segundo Scarano \& Esteves (2004). Araujo et al. (1998) reconhecem dez formações vegetacionais neste Parque: halófila-psamófila reptante; arbustiva fechada de pós-praia; arbustiva aberta de Clusia; arbustiva aberta de Ericaceae; mata periodicamente inundada; mata permanentemente inundada; mata de cordão arenoso; arbustiva aberta de Palmae; herbácea brejosa e aquática. A planície arenosa sobre a qual se desenvolveram essas formações formou-se pela justaposição de barras de areia depositadas sucessivamente paralelas ao longo da costa (Henriques et al. 1986), resultando em uma sucessão de cristas e de depressões no sentido do mar para o continente.

O inventário das espécies incluiu espécimes coletados em quatro excursões de campo em diferentes formações vegetacionais do PNRJ, entre 2005 e 2006. A estes, foram acrescidos espécimes depositados no herbário do Instituto de Pesquisas Jardim Botânico do Rio de Janeiro (RB) e aqueles com ocorrência registrada na literatura (Costa \& Yano 1998; Costa et al. 2006). A metodologia de coleta e herborização seguiu Gradstein et al. (2001) e as coleções estão depositadas nos herbários do Museu Nacional do Rio de Janeiro (R) e RB.

A identificação das hepáticas baseou-se principalmente em Lemos-Michel (2001) e Gradstein \& Costa (2003). Para os musgos consultou-se Yano et al. (1985), Frahm (1991), Reese (1993), Sharp et al. (1994) e Buck (1998). A classificação adotada segue CrandallStotler \& Stotler (2000) para as hepáticas e Goffinet \& Buck (2004) para os musgos.

Para cada táxon foram analisados a distribuição geográfica no mundo e no Brasil, o tipo de substrato e a forma de vida.

A distribuição geográfica mundial e no Brasil das espécies foram extraídas do Banco de Dados da brioflora do Estado do Rio de Janeiro (Instituto de Pesquisas Jardim Botânico do Rio de Janeiro 2008). A distribuição mundial foi considerada Pantropical quando a espécie ocorre em três ou mais continentes entre os trópicos e Neotropical quando ocorre em três ou mais países do Neotrópico. Os Estados da federação estão abreviados conforme sigla oficial do Instituto Brasileiro de Geografia e Estatística (IBGE).

A nomenclatura adotada para os tipos de substrato segue a de Robbins (1952), sendo consideradas corticícolas as espécies que crescem sobre troncos; epíxilas, sobre troncos em decomposição e terrícolas, sobre solo. Além dessas, foram consideradas aquáticas as plantas flutuantes sem contato com o solo.

A classificação das formas de vida é baseada em Mägdefrau (1982) e Gimingham \& Birse (1957), a saber: tapete - plantas com ramos principais e laterais fortemente aderidos ao substrato por rizóides; trama plantas cujos ramos crescem uns por sobre os outros, com gametófitos facilmente removíveis do substrato; tufo - plantas perpendiculares ao substrato e próximas entre si, pode ser curto (até $2 \mathrm{~cm}$ de comprimento) ou longo (mais de $2 \mathrm{~cm}$ de comprimento); pendentes plantas com eixo principal rastejante e ramos pendentes, crescendo sobre uma base vertical (tronco de árvore, por exemplo). Além dessas, foi considerada ainda a forma talosa, adaptada de Richards (1984), em que as plantas são aplanadas e não diferenciadas em caulídios e filídios. 


\section{Resultados e discussão}

No total são registrados 61 táxons de briófitas para o PNRJ, sendo 43 de hepáticas e 18 de musgos (Tab. 1), pertencentes a 15 famílias e 33 gêneros. Os números totais de táxons para o Brasil e para o Rio de Janeiro foram ampliados para 137 e 74, respectivamente, somando-se as novas ocorrências do presente estudo. Assim, as espécies do PNRJ correspondem a $45 \%$ dos táxons de briófitas conhecidas para as restingas no Brasil, $82 \%$ dos conhecidas para as restingas do estado do Rio de Janeiro, e 7\% da flora conhecida para o Parque. Estes valores salientam a importância do Parque para a conservação de espécies de briófitas de restinga no país e no estado e a grande representatividade das espécies de briófitas para sua flora.

A família com maior número de espécies foi Lejeuneaceae, com 25 espécies $(41 \%)$, o que foi observado também em outros inventários de brioflora realizados em restingas (e.g. Behar et al. 1992; Yano \& Costa 1993; Bastos \& Yano 2006) e em florestas tropicais úmidas de planície como um todo (Gradstein et al. 2001). A essa família se seguem Jubulaceae (sete espécies; $11 \%$ ), Calymperaceae e Sphagnaceae (ambas com quatro espécies cada, ou 7\%), que estão entre aquelas mais representativas de florestas tropicais úmidas de planície, com exceção de Sphagnaceae (Gradstein et al. 2001). Leucobryaceae, apesar de no Parque não aparecer entre as famílias mais expressivas, está presente em todas as restingas estudadas no Brasil, representada principalmente pelo gênero Campylopus, comumente encontrado no PNRJ sobre areia na periferia de moitas nas formações arbustivas de Ericaceae e Clusia. Algumas famílias de ocorrência incomum em restinga, como Aneuraceae e Ricciaceae, foram encontradas no PNRJ. Riccardia cataractarum, encontrada sobre solo encharcado na formação herbácea brejosa e apontada por Hell (1969) como característica de solos muito úmidos e, ocasionalmente, submersa. Ricciocarpos natans é flutuante em braço de lagoa no PNRJ. A presença desses táxons também corrobora a importância do PNRJ para conservação e manutenção da diversidade de briófitas de restinga do estado.

A maioria das espécies encontradas apresenta distribuição Neotropical (35\%), seguida da Pantropical (26\%) (Tab. 1), o que era esperado, tendo em vista que, segundo Tan \& Pócs (2000), briófitas de regiões tropicais apresentam padrão de distribuição predominantemente Neotropical ou Paleotropical. Destacam-se ainda 5 táxons com disjunção Afro-americana (e.g. Cheilolejeunea rigidula e Leucolejeunea unciloba), bem como três endêmicos do Brasil (Bromeliophila natans, Frullania vitalii e Lejeunea cristulata). Bromeliophila natans, uma espécie endêmica cuja localidade tipo está no Rio de Janeiro (Grolle 1985), não foi encontrada no presente estudo, e as últimas coletas foram realizadas há mais de 10 anos na Ilha do Cardoso (Schuster 1994; Grolle 1985) e em Ubatuba (Visnadi 1998), Estado de São Paulo. Com relação à distribuição das espécies no Brasil, a maioria (92\%) é registrada para três ou mais regiões do país, e $61 \%$ ocorre em todas as cinco regiões, demonstrando que a brioflora do Parque é composta em sua maioria por espécies de ampla ocorrência no Brasil.

A análise do tipo de substrato colonizado pelas briófitas revelou predominância de plantas corticícolas (77\%), seguido pelas terrícolas (38\%), epíxilas (25\%) e aquáticas (3\%), resultados similares aos encontrados por Bastos \& Yano (2006) em áreas de restinga no estado da Bahia. O elevado número de espécies corticícolas era esperado, visto que a disponibilidade desse tipo de substrato é alta. Por outro lado, o menor número de espécies terrícolas se deve à permanente camada de serrapilheira no solo das matas de restinga, que dificulta o estabelecimento das briófitas (Pócs 1982) e ao fato do solo arenoso ser inóspito para muitas espécies de briófitas. As espécies corticícolas estavam, em sua maioria, localizadas nas partes do tronco abaixo de $1 \mathrm{~m}$ de altura, com predomínio de hepáticas nas partes superiores e de musgos nas partes basais. As terrícolas foram observadas sobre areia na periferia de moitas ou solo de origem orgânica nas diferentes formações. A maioria das espécies (69\%) coloniza um único tipo de substrato, com $46 \%$ estritamente corticícolas, das quais somente três são musgos (Tab. 1) e $20 \%$ estritamente terrícolas, das quais três são hepáticas, Riccardia cataractarum e Arachniopsis monodactyla, de solo encharcado e Cephaloziella divaricata, de solo arenoso. Duas espécies são exclusivamente aquáticas, Ricciocarpos natans e Bromeliophila natans, e nenhuma é estritamente epíxila. Nas áreas inundáveis da formação arbustiva aberta de Ericaceae, o substrato terrícola se constitui de matéria orgânica particulada em decomposição acumulada em ilhas, na trama formada pelas raízes de Bonnetia stricta Mart. Nesse substrato foram encontradas diversas espécies de briófitas com cobertura expressiva, dentre as quais destacam-se Telaranea diacantha e Arachniopsis monodactyla, sendo esta última restrita no Parque a essas ilhas de matéria orgânica.

Quanto às formas de vida, foram encontrados cinco tipos: tapete, tufo (curto e longo), trama, pendente e talosa (Tab. 1). As formas de vida são reconhecidas por diversos autores como estando fortemente relacionadas às condições de umidade e luminosidade do ambiente (Mägdefrau 1982; Bates 1998; Kürschner et al. 1999; entre outros). Tapete predominou (49\%), seguido por 


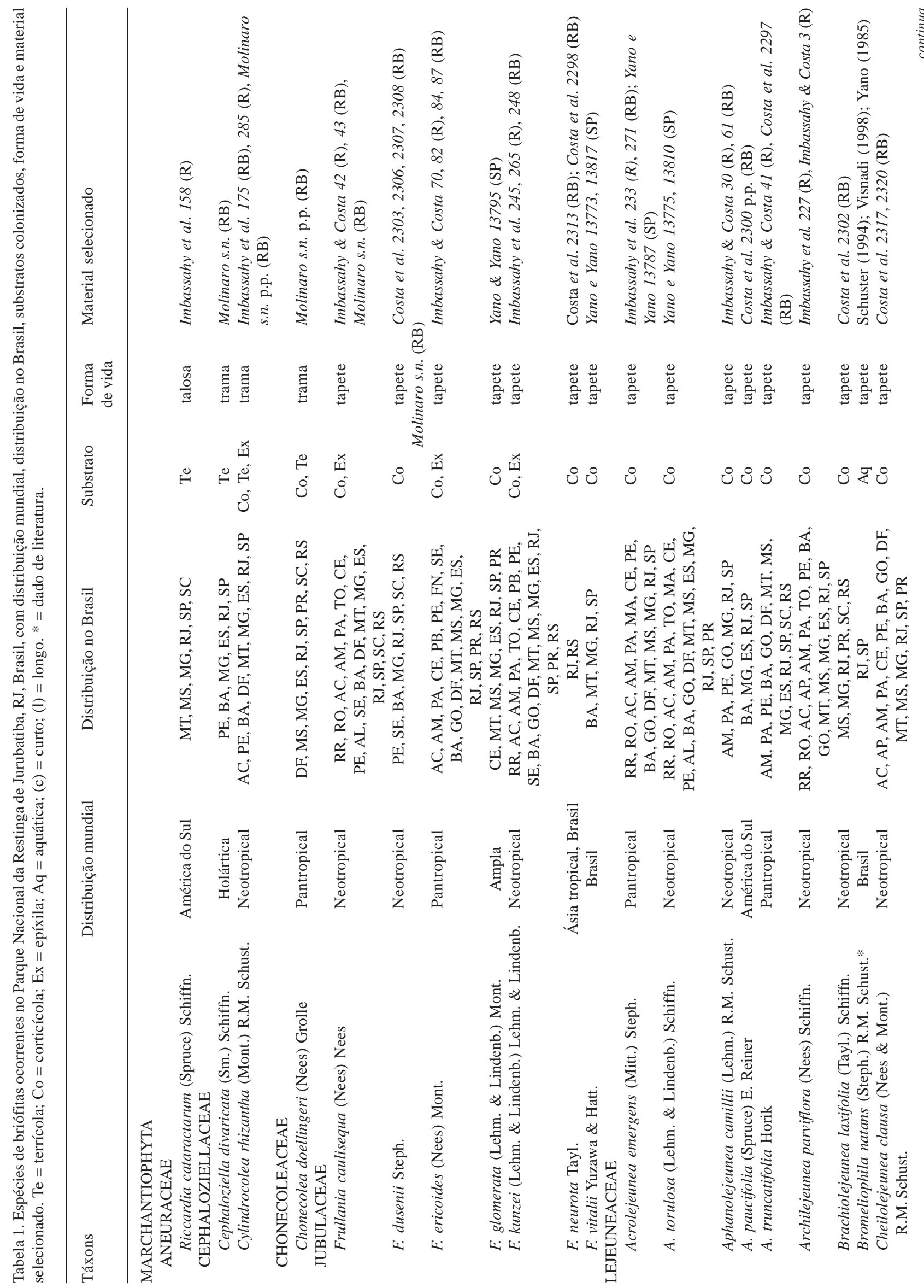




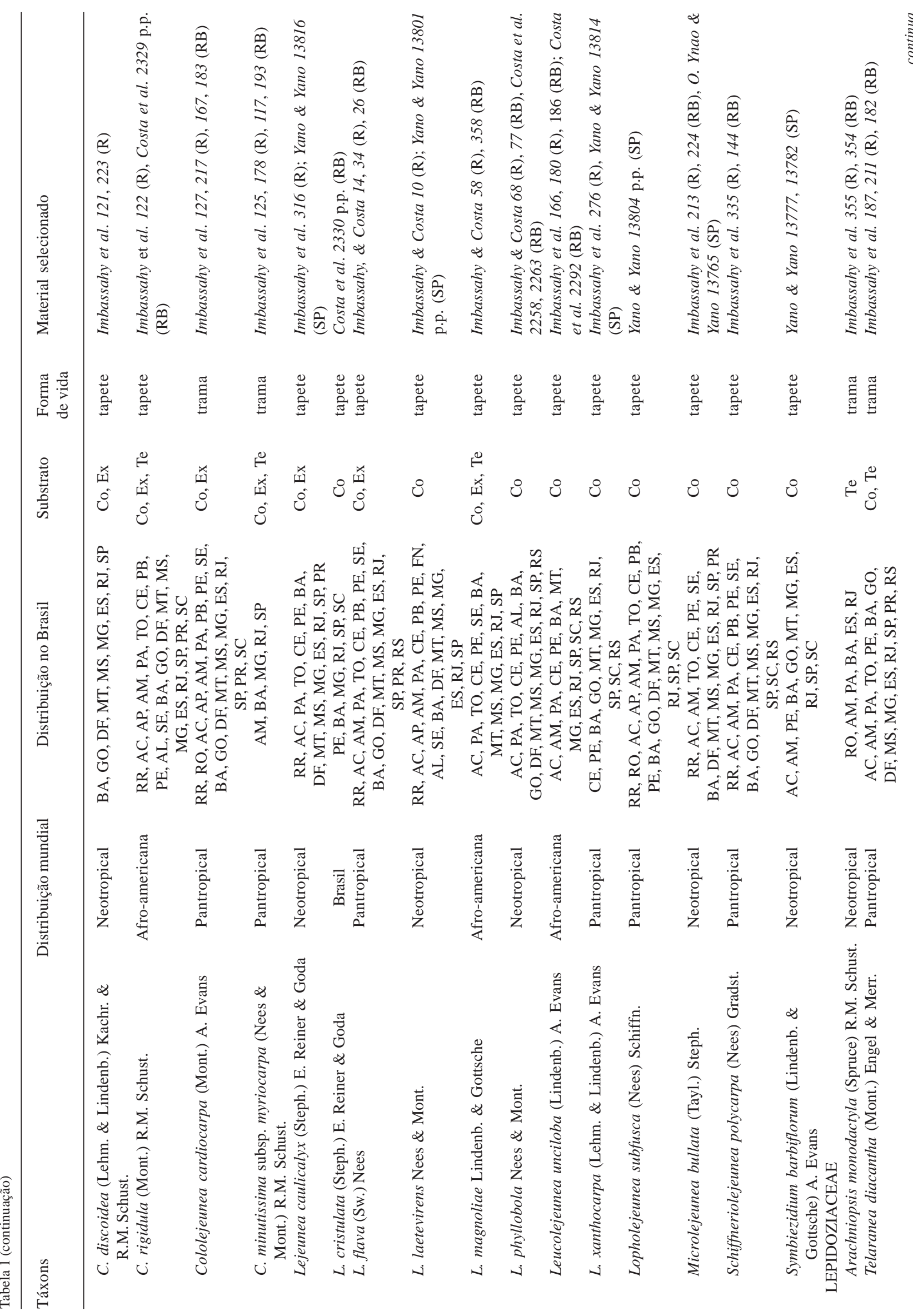




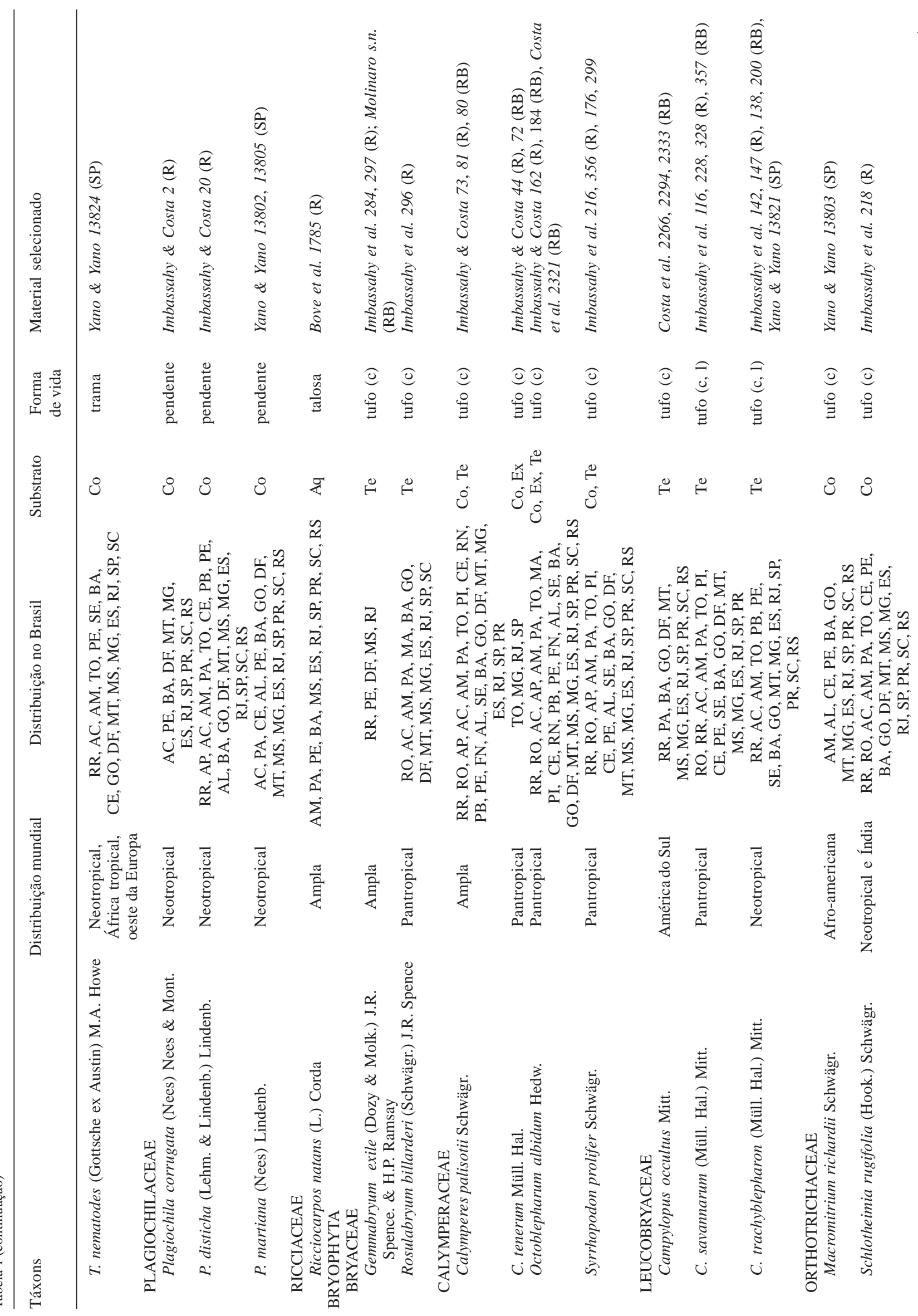


tufo $(25 \%)$ e trama $(18 \%)$, o que era esperado, visto que na área predominam plantas corticícolas, e segundo Mägdefrau (1982), tapete é uma forma de vida característica de troncos de árvores. De acordo com Frahm (2003), os tapetes são eficientes como armazenadores de água, sendo característicos de habitats sujeitos à dessecação ocasional, como, por exemplo, superfícies lisas de rochas e troncos. A maioria das espécies que apresentaram a forma de vida tufo curto foram encontradas sobre solo arenoso e em áreas com intensa exposição à luminosidade, como as formações abertas de Palmae e de Clusia, o que era esperado visto que esse tipo de forma de vida está relacionado a ambientes secos (Mägdefrau 1982). Os tufos longos só foram observados em áreas bastante úmidas, como brejos e alagados (e.g. Sphagnum), ou áreas sombreadas, como o interior de moitas ou da mata (e.g. Sphagnum e Campylopus). Os musgos Campylopus trachyblepharon e C. savannarum foram observados como tufo curto ou longo, variando de tamanho de acordo com as condições do ambiente em que foram encontrados. As formas dos tipos pendente $(5 \%)$ e trama contam com menos representantes, visto que estão relacionadas a ambientes com alta disponibilidade de umidade atmosférica (Bates 1998). As briófitas pendentes ocorrem principalmente em florestas tropicais nebulosas (Gradstein \& Pócs 1989) e foram encontradas somente na mata periodicamente inundada, provavelmente a formação com maior umidade relativa. A forma talosa (3\%) foi observada em ambientes com grande disponibilidade de água, como lâmina d'água de lagoas, a exemplo da hepática flutuante Ricciocarpos natans, e solo encharcado da formação herbácea brejosa, no caso de Riccardia cataractarum. Entre as hepáticas, predominou o tipo tapete e entre os musgos o tipo tufo curto, que são típicos de ambientes com baixa disponibilidade de água.

Analisando a distribuição das espécies nas diferentes formações vegetacionais do PNRJ, pode-se constatar que a riqueza é maior nas formações fechadas e de porte arbustivo-arbóreo, como a mata periodicamente inundada e as áreas inundáveis da restinga arbustiva aberta de Ericaceae, onde encontram-se diversas espécies de Lejeuneaceae e os gêneros Aphanolejeunea e Plagiochila, somente observados nessas formações. Nas formações arbustivas abertas de Palmae e de Clusia, há um menor número de espécies, e predominam os gêneros Frullania e Campylopus. A diferença entre as riquezas das áreas fechadas e abertas pode ser devido ao grau de exposição dessas vegetações ao sol e vento, o que influenciaria os índices locais de umidade e luminosidade, fatores que reconhecidamente interferem no desenvolvimento de briófitas (Mägdefrau 1982). Geralmente, predominam espécies tolerantes a baixos 
índices de umidade, alta luminosidade e temperaturas, como por exemplo, Cololejeunea cardiocarpa e Cololejeunea minutissima subsp. myriocarpa, apontadas por Gradstein et al. (2001) como típicas de florestas semi-decíduas, savanas e áreas cultivadas, e Frullania kunzei, típica de ambientes expostos à ação do sol e ventos (Lemos-Michel 2001). Gemmabryum exile, uma espécie que pode ser ruderal segundo Ochi (1980), foi encontrada somente na formação arbustiva aberta de Palmae, que se estabelece em locais onde a vegetação original foi removida (Araujo et al. 1998).

De uma maneira geral, a flora de briófitas do PNRJ é constituída de espécies típicas de mata atlântica e com padrões de distribuição abrangentes, (Neotropical, Pantropical e Amplo), como por exemplo, Cephaloziella divaricata, Isopterygium tenerum e Sematophyllum subpinnatum. Apesar disso, o Parque apresenta também espécies que são conhecidas somente para essa restinga, como Aphanolejeunea camillii, Riccardia cataracatrum, Ricciocarpos natans e Sphagnum sparsum. É provável que a grande diversidade de formações vegetacionais presentes no PNRJ contribua para esta expressiva riqueza de espécies, uma vez que muitas se encontram ainda em bom estado de conservação e são raras em outras restingas do país, como as formações inundáveis, brejosas e as lagoas, que em geral se encontram altamente impactadas pela ação do homem. Esses dados reforçam a importância do Parque para a conservação das espécies de briófitas de restinga e apontam para a necessidade de estudos semelhantes em outras restingas do país.

Chave para identificação das espécies de briófitas do Parque Nacional da Restinga de Jurubatiba

1. Plantas talosas ou folhosas, com os filídios dísticos, dispostos em duas fileiras laterais e uma ventral, ou apenas em duas fileiras laterais Marchantiophyta (Hepáticas) 2

2. Plantas talosas

3. Plantas aquáticas, flutuantes; talo com muitas células de espessura, câmaras aeríferas presentes

. Plantas terrícolas, prostradas; talo com 4-6 células de espessura, sem câmaras aeríferas Ricciocarpos natans Riccardia cataractarum

2. Plantas folhosas 4

4. Filídios filamentosos 5

5. Filídios constituídos por 1 filamento; filamentos constituídos por 1(-2) células . Arachniopsis monodactyla

5. Filídios constituídos por 2-4 filamentos; filamentos constituídos por 1-8 células

6. Filídios no caulídio principal com 2 filamentos com papilas hialinas nos ápices; anfigastros ausentes ou, quando presentes, constituídos por 2 células adjacentes

6. Filídios no caulídio principal com 3-4 filamentos sem papilas hialinas nos ápices; anfigastros 2-3 lobados, cada um constituído por 2-3 células de comprimento

Telaranea nematodes

4. Filídios compostos por lâminas

7. Anfigastros presentes e conspícuos.....

8. Lóbulos dos filídios ligados ao lobo através de uma quilha em quase todo o seu comprimento

9. Anfigastros bífidos

10. Lóbulos ca. $2 / 3$ do lobo Microlejeunea bullata

10. Lóbulos $<1 / 2$ do lobo 11

11. Filídios assimétricos, lanceolados, com ápice acuminado; plantas aquáticas, encontradas nas axilas de folhas de bromélias Bromeliophila natans

11. Filídios simétricos, orbiculares a ovados, com ápice obtuso a orbicular; plantas corticícolas, epíxilas ou terrícolas 12

12. Lóbulo com papila hialina distal no dente apical 13

13. Plantas dióicas, 0,7-1,2 mm de largura, trigônios conspícuos 14 14. Anfigastros distantes, oblongos a obovados, base cuneada . Cheilolejeunea rigidula

14. Anfigastros contíguos a imbricados, orbiculares, base cordada . Cheilolejeunea clausa 
13. Plantas autóicas, ca. $0,5 \mathrm{~mm}$ de largura, trigônios inconspícuos Cheilolejeunea discoidea

12. Lóbulo com papila hialina proximal no dente apical ................................................ 15 15. Plantas com filídios caducos ............................................... Lejeunea phyllobola

15. Plantas com filídios persistentes .................................................................... 16

16. Anfigastros geralmente 3 vezes ou mais largos que o caulídio

16. Anfigastros menos de 3 vezes mais largos que o caulídio.......................... 17

17. Filídios inseridos no caulídio de forma oblíqua ..... Lejeunea laetevirens

17. Filídios inseridos no caulídio em ângulo reto ........................................ 18

18. Quilha arqueada ............................................... Lejeunea cristulata

18. Quilha reta. 19

19. Sinus dos anfigastros em forma de "U" até lunulados, 2/3-4/5 do comprimento total do anfigastro; margem dos filídios inteiras ou levemente crenuladas Lejeunea magnoliae

19. Sinus dos anfigastros geralmente com forma de "V", nunca lunulados, com menos da $1 / 2$ do comprimento do anfigastro; margem dos filí́dios fortemente crenulada Lejeunea caulicalyx

9. Anfigastros inteiros 20

20. Células da lâmina mais longas do que largas; trigônios cordados ..... 21

21. Anfigastro com base decurrente, inserção numa linha fortemente arqueada; inovações presentes Brachiolejeunea laxifolia

21. Anfigastro com base não decurrente, inserção numa linha reta ou ligeiramente recurvada; inovações ausentes

22. Lóbulo com 2/5-1/2 do comprimento do lobo, (2-)3-8 dentes (observar diversos filídios); filídios caducos presentes

23. Lóbulos com (2-)3-4 dentes Acrolejeunea emergens

23. Lóbulos com 5-8 dentes Acrolejeunea torulosa

22. Lóbulo com 1/3-2/5 do comprimento do lobo, 1-2 dentes (observar diversos filídios); sem filí́dios caducos Schiffneriolejeunea polycarpa

20. Células da lâmina isodiamétricas; trigônios triangulares ou radiados 24

24. Lóbulos com 1-3 dentes; oleocorpos granulares (observar em material fresco)

25. Plantas de coloração verde a castanho-escura; margem ventral dos lobos plana; merófito ventral com 4-6(-8) células de largura Archilejeunea parviflora

25. Plantas de coloração verde-esbranquiçada; margem ventral dos lobos recurvadas; merófito ventral com 2-4 células de largura 26

26. Margem do lobo plana ou ligeiramente recurvada, dente apical conspícuo e alongado Leucolejeunea unciloba

26. Margem do lobo fortemente involuta, dente apical inconspícuo e curto Leucolejeunea xanthocarpa

24. Lóbulos sem dente ou com dente único inconspícuo e arredondado; oleocorpos homogêneos não segmentados (observar em material fresco)

27. Filídios arredondados; lóbulos medianos, ocupando mais do que 1/4 do comprimento do lobo Lopholejeunea subfusca

27. Filídios alongados; lóbulos pequenos, ocupando menos de 1/4 do comprimento do lobo, inflado-arredondado Symbiezidium barbiflorum

8. Lóbulos dos filídios quase livres do lobo, quilha ausente 28 28. Filídios com numerosos ocelos Frullania vitalii 28. Filídios sem ocelos 29 
29. Lóbulos separados do caulídio por pelo menos sua própria largura

Frullania caulisequa

29. Lóbulos separados do caulídio por menos do que sua própria largura

30. Todos os lóbulos laminares ou cilíndricos, lóbulos sacados ausentes

Frullania kunzei

30. Todos ou alguns lóbulos sacados, aqueles não sacados laminares ............................ 31

31. Lóbulos sacados com segmento laminar basal ............................................... 32

32. Anfigastros com largura ca. três vezes a largura do caulídio; segmento laminar basal curto-estreitado; estilete filiforme diminuto, com 2-3 células de comprimento Frullania dusenii

32. Anfigastros com largura menor do que o dobro da largura do caulídio; segmento laminar basal longo-triangular; estilete filiforme com 4-6 células de comprimento Frullania neurota

31. Lóbulos sacados sem segmento laminar basal 33

33. Filídios distintamente esquarrosos quando úmidos; estiletes filiforme, 4-7 células de comprimento, unisseriados ou algumas vezes com 2 células na base Frullania ericoides

33. Filídios não esquarrosos quando úmidos; estiletes folhosos, 7-10 células de comprimento, na metade superior unisseriados e na metade inferior com 2-5 células de largura

Frullania glomerata

7. Anfigastros ausentes ou inconspícuos 34

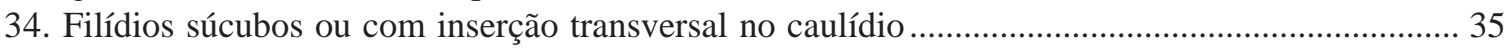

35. Filídios bífidos; trigônios ausentes

36. Filídios transversos Cephaloziella divaricata

36. Filídios súcubos 37

37. Filídios contíguos e transversos, linha de inserção alcançando a linha mediana dorsal do caulídio Chonecolea doellingeri

37. Filídios distantes e laterais, linha de inserção não alcançando a linha mediana dorsal do caulídio Cylindrocolea rhizantha

35. Filídios inteiros; trigônios conspícuos 38

38. Margem ventral crispado-ondulada Plagiochila corrugata

38. Margem ventral plana 39

39. Margem ventral do filídio denteada Plagiochila disticha 39. Margem ventral do filídio inteira Plagiochila martiana

34. Filídios íncubos 40

40. Filídios de um único tipo na mesma planta, sempre com lóbulos; ramos com colar na base

41. Filídios com células marginais hialinas na extremidade do lobo; lóbulos 1/4-1/3 do tamanho do lobo Cololejeunea cardiocarpa

41. Filídios sem células marginais hialinas na extremidade do lobo; lóbulos ca. $1 / 2$ do tamanho do lobo Cololejeunea minutissima subsp. myriocarpa

40. Filídios de dois tipos na mesma planta, com lóbulos ou sem lóbulos; ramos sem colar na base

42. Filídios com 2-3 lóbulos bem desenvolvidos; ápice dos filídios truncado ou obtuso Aphanolejeunea trucatifolia

42. Filídios em sua maioria com lóbulos reduzidos; ápice dos filídios acuminado a agudo

43. Filídios elípticos, rômbicos ou lanceolados, mais largos na região mediana; ápice agudo, terminado por uma célula Aphanolejeunea camillii

43. Filídios ovados, mais largos na região basal; ápice acuminado e geralmente curvado, terminado por 3-4 células Aphanolejeunea paucifolia

1. Plantas folhosas, com os filídios dispostos espiraladamente no caulídio Bryophyta (Musgos) 44 44. Plantas de locais alagados; com ramos em fascículos; costa ausente; lâmina do filídio 
uniestratificada, formada por uma trama de clorocistos (células pequenas e clorofiladas) e leucocistos (células grandes e hialinas).....

45. Filídios dos ramos côncavos, cuculados, ápice arredondado, margem fortemente involuta

46. Células corticais fortes a fracamente fibrilosas, com 1-2 poros; clorocistos mais expostos na face ventral do filídio (em corte transversal, situados mais próximos de uma das superfícies e de formato triangular) Sphagnum palustre

46. Células corticais afibrilosas a fracamente fibrilosas, com 1 poro apical; clorocistos expostos em ambas as faces do filídio (em corte transversal, eqüidistantes às superfícies ventral e dorsal e de formato retangular)..... Sphagnum perichaetiale

45. Filídios dos ramos aplanados, não cuculados, ápice acuminado e denticulado, margem ligeiramente involuta na metade superior

47. Filídios dos ramos linear-lanceolados; clorocistos em secção transversal expostos na superfície dorsal. Sphagnum cuspidatum

47. Filídios dos ramos ovado-lanceolados; clorocistos em secção transversal expostos na superfície ventral Sphagnum sparsum

44. Plantas de locais secos, eventualmente sobre areia úmida, ramos não dispostos em fascículos; costa presente ou ausente; lâmina do filídio uni- a multiestratificada, sem as demais características ................ 48 48. Musgos pleurocárpicos; filídios sem costa ou com costa curta e dupla .....

49. Células da lâmina romboidais, 3-12:1; células alares diferenciadas (maiores e infladas) 50

50. Filídios ovados a oblongo-ovados; células apicais da lâmina curtas, 2-3:1 Sematophyllum subpinnatum

50. Filídios lanceolados a oblongo-lanceolados; células apicais da lâmina mais longas, 4-6:1 Sematophyllum adnatum

49. Células da lâmina lineares, 16-25:1; células alares não diferenciadas Isopterygium tenerum

48. Musgos acrocárpicos; filí́dios com costa simples 51

51. Caulídios rastejantes, com numerosos ramos ascendentes 52

52. Plantas marrom-escuras, avermelhadas; filídios oblongo-ovados a oblongo-ligulados; lâmina rugosa Schlotheimia rugifolia

52. Plantas verde-claras a verde-escuras; filídios ligulados a ligulado-lanceolados; lâmina lisa .....

51. Caulídios eretos, com ramos laterais ou ausentes 53

53. Plantas de coloração verde a verde-esbranquiçada; costa larga ocupando quase a totalidade do filídio, lâmina restrita a base Octoblepharum albidum

53. Plantas de coloração verde, verde-amareladas a verde-escuras; costa delgada, lâmina ocupando quase a totalidade do filídio ..... 54

54. Região basal da lâmina dos filídios com células cancelinas; tufos de gemas ocasionalmente no ápice da costa 55

55. Filídios lineares a lanceolados; margem bordeada por células hialinas Syrrhopodon prolifer

55. Filídios oblongos a oblongo-lanceolados; margem não bordeada por células hialinas. 56

56. Teníola conspícua na região do ombro para o ápice; filídios gemíparos com costa percurrente e gemas crescendo em tufos na superfície ventral do ápice da costa Calymperes palisotii

56. Teníola ausente ou vestigial; filídios gemíparos com costa excurrente e gemas no ápice da costa formando uma estrutura esférica....... Calymperes tenerum

54. Região basal da lâmina dos filídios sem células cancelinas; sem tufos de gemas no ápice da costa 57

57. Filídios lanceolados ou linear-lanceolados; costa ocupando um terço ou mais da largura do filídio na base; células alares diferenciadas Campylopus trachyblepharon 58. Costa com lamelas em seção transversal 58. Costa sem lamelas em seção transversal 59 59. Filídios linear-lanceolados, costa ocupando ca. $1 / 2$ da largura do 
filídio na base. Campylopus savannarum

59. Filídios ovados na base e lanceolados no ápice, costa ocupando ca.

$1 / 3$ da largura do filídio na base Campylopus occultus

57. Filídios ovados a oblongo-ovados, obovados ou espatulados; costa ocupando menos de um terço da largura do filídio na base; células alares não diferenciadas

60. Plantas verde-claras; filídios em roseta no ápice do caulídio, obovados

a espatulados; costa percurrente a curto-excurrente Rosulabryum billarderi

60. Plantas verde-escuras; filídios igualmente dispostos ao longo do caulí-

dio, ovados a oblongo-ovados; costa longo-excurrente Gemmabryum exile

\section{Agradecimentos}

O primeiro Autor agradece à CAPES, pela bolsa de mestrado concedida; aos colegas Wallace de Castro, Maria Colodete e Thaís Imbassahy, pelo auxílio no trabalho de campo. Os autores agradecem ao Programa Brasileiro de Pesquisas Ecológicas de Longa Duração, pelo auxílio financeiro às excursões de campo e ao Instituto de Pesquisas Jardim Botânico do Rio de Janeiro, pelo acesso a toda a sua infra-estrutura, inclusive a cessão do carro utilizado nos trabalhos de campo; aos revisores anônimos pelas sugestões ao presente manuscrito.

\section{Referências bibliográficas}

Araujo, D.S.D. \& Maciel, N.C. 1998. Restingas fluminenses: biodiversidade e preservação. Boletim FBCN 25: 27-51.

Araújo, D.S.D.; Scarano, F.R.; Sá, C.F.C.; Kurtz, B.C.; Zaluar, H.L.T.; Montezuma, R.C.M. \& Oliveira, R.C. 1998. Comunidades vegetais do Parque Nacional da Restinga de Jurubatiba. Pp. 39-62. In: F.A. Esteves (ed.). Ecologia das lagoas costeiras do Parque Nacional da Restinga de Jurubatiba e do município de Macaé. Rio de Janeiro, Universidade Federal do Rio de Janeiro.

Bastos, C.J.P. \& Yano, O. 2006. Briófitas de restinga das regiões Metropolitana de Salvador e Litoral Norte do Estado da Bahia, Brasil. Boletim do Instituto de Botânica 18: 197-205.

Bates, J.W. 1998. Is 'life form' a useful concept in bryophyte ecology? Oikos 82: 223-237.

Behar, L.; Yano, O. \& Vallandro, C.G. 1992. Briófitas da restinga de Setiba, Guarapari, Espírito Santo. Boletim do Museu de Biologia Mello Leitão, Nova Série 1: 25-38.

Buck, W.R. 1998. Pleurocarpous mosses of the West Indies. Memoirs of The New York Botanical Garden 82: 1-400.

Costa, A.F. \& Dias, I.C.A. (orgs.). 2001. Flora do Parque Nacional da Restinga de Jurubatiba e arredores, Rio de Janeiro, Brasil: listagem, florística e fitogeografia. Série Livros 8 . Museu Nacional, Universidade Federal do Rio de Janeiro, Rio de Janeiro.

Costa, D.P.; Imbassahy, C.A.A.; Almeida, J.S.S.; Santos, N.D. \& Imbassahy, T.F.V. 2006. Diversidade das briófitas nas restingas do estado do Rio de Janeiro, Brasil. Boletim do Instituto de Botânica 18: 131-139.

Costa, D.P. \& Yano, O. 1998. Briófitas da restinga de Macaé, Rio de Janeiro, Brasil. Hoehnea 25: 99-119.
Crandall-Stotler, B. \& Stotler, R.E. 2000. Morphology and classification of the Marchantiophyta. Pp. 21-70. In: A.J. Shaw \& B. Goffinet (eds.). Bryophyte Biology. Cambridge, Cambridge University Press.

Esteves, F.A.; Scarano, F.R. \& Furtado, A.L.S. 2002. Restingas e lagoas costeiras do Norte Fluminense, Site 5. Pp. 83-97. In: U. Seeliger; C. Cordazzo \& F. Barbosa (eds.). Os Sites e o Programa Brasileiro de Pesquisas Ecológicas de Longa Duração. Belo Horizonte, PELD.

Frahm, J.-P. 1991. Dicranaceae: Campylopodioideae, Paraleucobryoideae. Flora Neotropica, Monograph 54: 1-238.

Frahm, J.-P. 2003. Manual of Tropical Bryology: Morphological adaptations. Tropical Bryology 23: 29-38.

Fundação SOS Mata Atlântica/Instituto Nacional de Pesquisas Espaciais 2002. Atlas dos Remanescentes Florestais da Mata Atlântica: período 1995-2000. São Paulo, Fundação SOS. Mata Atlântica/INPE.

Gimingham, C.H. \& Birse, E.M. 1957. Ecological studies on growthform in bryophytes: 1. Correlations between growth-form and habitat. Journal of Ecology 45: 533-545.

Goffinet, B. \& Buck, W.R. 2004. Systematics of the Bryophyta (Mosses): from molecules to a revised classification. Pp. 206-239. In: B. Goffinet; V. Hollowell \& R. Magill (eds.). Molecular Systematics of Bryophytes. St. Louis, Missouri Botanical Garden.

Gradstein, S.R. \& Pócs, T. 1989. Bryophytes. Pp. 311-325. In: H. Lieth \& M.J.A. Werger. Tropical Rain Forest Ecosystems. Amsterdan, Elsevier.

Gradstein, S.R.; Churchill, S.P. \& Salazar-Allen, N. 2001. Guide to the bryophytes of tropical America. Memoirs of The New York Botanical Garden 86: 1-577.

Gradstein, S.R. \& Costa, D.P. 2003. The hepaticae and anthocerotae of Brazil. Memoirs of The New York Botanical Garden 87: $1-318$.

Grolle, R. 1985. Miscellanea hepaticologica. 231-240. Journal of the Hattori Botanical Laboratory 58: 197-202.

Jamel, C.E.G. 2004. Caracterização da vegetação da Restinga de Jurubatiba com base em sensoriamento remoto e Sistema de Informação Geográfico: estado atual e perspectivas. Pp. 25-42. In: C.F.D. Rocha; F.A. Esteves \& F.R. Scarano. Pesquisas de Longa Duração na Restinga de Jurubatiba - Ecologia, História natural e Conservação. São Carlos, Rima.

Henriques, R.P.B.; Araujo, D.S.D. \& Hay, J.D. 1986. Descrição e classificação dos tipos de vegetação da restinga de Carapebus, Rio de Janeiro. Revista Brasileira de Botânica 9: 173-189

Instituto de Pesquisas Jardim Botânico do Rio de Janeiro (Briófitas). 2008. http://www.jbrj.gov.br/pesquisa/div_tax/ briofitas (Acesso em: 24/06/2008). 
Kürschner, H.; Frey, W. \& Parolly, G. 1999. Patterns and adaptive trends of life forms, life strategies and ecomorphological structures in tropical epiphytic bryophytes - a pantropical synopsis. Nova Hedwigia 69: 73-99.

Lacerda L.D.; Araujo, D.S.D.; Cerqueira, R. \& Turq, B. (orgs.). 1984. Restingas: origem, estrutura e processos. Niterói, CEUFF.

Lacerda, L.D.; Araujo, D.S.D. \& Maciel, N.C. 1993. Dry coastal ecosystems of the tropical Brazilian coast. In: E. van der Maarel (ed.). Dry coastal ecosystems: Africa, America, Asia, Oceania. Amsterdam, Elsevier.

Lemos-Michel, E. 2001. Hepáticas epifíticas sobre o pinheirobrasileiro no Rio Grande do Sul. Rio Grande do Sul, Editora da Universidade Federal do Rio Grande do Sul.

Mägdefrau, K. 1982. Life-forms of bryophytes. Pp. 45-58. In: A.J.E. Smith (ed.). Bryophyte Ecology. London, Chapman and Hall.

Muehe, D. \& Valentini, E. 1998. O litoral do estado do Rio de Janeiro: uma caracterização físico-ambiental. Rio de Janeiro, FEMAR - SEMA/GTZ.

Ochi, H. 1980. A revision of the neotropical Bryoïdeae, Musci (First part). The Journal of the Faculty of Education - Natural Science 29: 49-154.

Pócs, T. 1982. Tropical forest bryophytes. Pp. 59-104. In: A.J.E. Smith (ed.). Bryophyte Ecology. London, Chapman and Hall.

Reese, W.D. 1993. Calymperaceae. Flora Neotropica, Monograph 58: $1-102$.

Richards, P.W. 1984. The ecology of tropical forest bryophytes. Pp. 1233-1270. In: R.M. Schuster (ed.). New Manual of Bryology. Nichinan, Hattori Botanical Laboratory.

Robbins, R.G. 1952. Bryophyte ecology of a dune area in New Zealand. Vegetatio, Acta Geobotanica 4: 1-31.
Scarano, F.R. \& Esteves, F.A. 2004. Pesquisas Ecológicas de Longa Duração na Restinga de Jurubatiba: Hipótese central, estratégia de pesquisa e perspectivas. Pp. 15-22. In: C.F.D. Rocha; F.A. Esteves \& F.R. Scarano. Pesquisas de Longa Duração na Restinga de Jurubatiba - Ecologia, História Natural e Conservação. São Carlos, Rima.

Schuster, R.M. 1994. Studies on Lejeuneaceae, I. Preliminary studies on new genera of Lejeuneaceae. Journal of the Hattori Botanical Laboratory 75: 211-235.

Sharp, A.J.; Crum, H.A. \& Eckel, P.M. (eds.). 1994. The moss flora of Mexico. Memoirs of The New York Botanical Garden 69: 1-1113.

Tan, B.C. \& Pócs, T. 2000. Bryogeography and conservation of bryophytes. Pp. 403-448. In: A.J. Shaw \& B. Goffinet (eds.). Bryophyte Biology. Cambridge, Cambridge University Press.

Visnadi, S.R. 1998. Briófitas em ecossistemas costeiros do núcleo Picinguaba do Parque Estadual da Serra do Mar, Ubatuba, SP. Tese de Doutorado em Ciências Biológicas. São Paulo, Universidade Estadual Paulista.

Visnadi, S.R. \& Vital, D.M. 1995. Bryophytes from restinga in Setiba State Park, Espírito Santo State, Brazil. Tropical Bryology 10: 69-74.

Visnadi, S.R. 2004. Briófitas de praias do estado de São Paulo, Brasil. Acta Botanica Brasilica 18: 91-97.

Vital, D.M. \& Visnadi, S.R. 1993. Briófitas de um trecho de restinga da Estação Ecológica da Juréia, Peruíbe, Estado de São Paulo, Brasil. Anais do III Simpósio de Ecossistemas da Costa Brasileira, São Paulo, ACIESP.

Yano, O. \& Costa, D.P. 1993. Briófitas da restinga da Massambaba, Rio de Janeiro. Anais do III Simpósio de Ecossistemas da Costa Brasileira. São Paulo, ACIESP.

Yano, O.; Pirani, J.R. \& Santos, D.P. 1985. O gênero Sphagnum (Bryopsida) nas regiões Sul e Sudeste do Brasil. Revista Brasileira de Botânica 8: 55-80.

Yano, O. \& Peralta, D.F. 2004. Briófitas da restinga de Barra do Ribeira, São Paulo, Brasil. Anais do VI Simpósio de Ecossistemas Brasileiros. São Paulo, ACIESP, v. 2, p. 573-587. 